\title{
COPERNICUS KNOWLEDGE AND INNOVATION HUBS
}

\author{
B. Riedler ${ }^{1 *}$, S. Lang ${ }^{1}$, P. Zeil ${ }^{2}$, M. Miguel-Lago ${ }^{3}$, C. Schröder ${ }^{4}$, N. Politi-Stergiou ${ }^{5}$, M. Kerschbaumer ${ }^{2}$, V. Tramutoli ${ }^{6}$, M. \\ Tzouvaras 7,8
}

${ }^{1}$ Dept. of Geoinformatics Z_GIS, University of Salzburg, Austria - (barbara.riedler, stefan.lang)@sbg.ac.at

${ }^{2}$ Spatial Services GmbH, Austria - (peter.zeil, markus.kerschbaumer)@spatial-services.com

${ }^{3}$ EARSC, European Association of Remote Sensing Companies, Belgium - monica.miguel-lago@earsc.org

${ }^{4}$ European Topic Centre, University of Malaga, Spain - christoph.schroder@uma.es

${ }^{5}$ Evenflow Consulting, Belgium - nefeli@evenflowconsulting.com

${ }^{6}$ School of Engineer, University of Basilicata, Italy - valerio.tramutoli@unibas.it

${ }^{7}$ Department of Civil Engineering and Geomatics, Faculty of Engineering and Technology, Cyprus University of Technology, Cyprus - marios.tzouvaras@cut.ac.cy

${ }^{8}$ Eratosthenes Centre of Excellence, Limassol, Cyprus

\section{Commission V, WG VI/2}

KEY WORDS: Copernicus Academy, CopHub.AC, Copernicus services, digital hubs, knowledge landscape, innovation monitor, skills programme

\begin{abstract}
:
Copernicus, the European Space program ensures free data availability and the organisational and financial framework to provide standardized information products in its service domains atmosphere, marine, land monitoring, climate change, emergency management and human security. A key to success to the market uptake process is knowledge exchange among all actors from the various sectors involved, notably research and educational institutions, industry, and the public sector. As a successful instrument to foster and stimulate this exchange, maximize the impact and additionally boost related capacity building and training activities, the Copernicus Academy has been anchored in the European Space Strategy. The present paper highlights some key activities to leverage the potential of this dynamically growing network of experts from universities and research institutions, public and private organizations, companies, stakeholders, and increase the benefit to its members. The vision of establishing both physical implementations of regional Copernicus hubs and virtual Copernicus hubs, built on key elements of the European Innovation strategy, is discussed. Regional hubs, attached e.g. to centres of excellence, are essential to meet local needs for exchange and training to boost the user uptake. The increasing importance of virtual hubs is becoming evident as a critical means to maximise synergies among actors in the rapidly advancing technological areas. Proposed technical elements demonstrate innovative solutions to visualize and facilitate easy harvesting of the Copernicus Academy member's expertise for different stakeholder and the public, and show cast possibilities of active involvement and exchange within the network.
\end{abstract}

\section{INTRODUCTION}

\subsection{Copernicus}

In the current European Space Strategy "Space research matters" (European Commission, 2016a) the uptake of information services is a key element. The Copernicus programme (www.copernicus.eu/) - as the joint space contribution of the European Commission (EC) and the European Space Agency (ESA) to the Global Earth Observation System of Systems (GEOSS) - is a successful role model, serving the needs of Europe's policy makers and embracing the important role of the user uptake. Data and services derived from Earth observation (EO) systems potentially combined with satellite navigation and satellite-based telecommunication, contribute to several public policies and economic sectors such as environmental protection, transport safety, precision farming, control of fishery stocks and detection of oil spills, to urban and regional planning. New fields of applications are constantly emerging including tourism, cultural heritage, smart cities, or humanitarian assistance, to name a few.

To stimulate user uptake within the Copernicus ecosystem, a variety of sub-programmes are in place, ranging from start-up and business funding, in form of the Copernicus Accelerator, ESA Space Solutions, Copernicus Incubator Programme and Copernicus Pilot Programme, over national initiatives to general awareness events, citizen involvement initiatives like Copernicus hackathons, as well as skills and networking programmes, such as the Copernicus Masters and high-level information and training session. The strong focus on the user uptake component strives to leverage on the huge preinvestments to ensure free data availability. Together with the organisational and financial framework, a reliable set of fundamental information services is provided and market

* Corresponding author 
uptake in the downstream sector complements this portfolio. Meanwhile, Copernicus data deliver wide benefits to citizens and society around the world for diverse applications and developing businesses and jobs. Experience shows there is a clear need for a systemic and integrated framework to ensure continuity and sustainability of these initiatives. Still, the diversity of the (potential) user communities in public and private sectors and within public authorities cause user uptake initiatives to be complex to manage. In the framework of the Copernicus user uptake activities, the EC identified strengths and gaps from existing user and market uptake initiatives across the Copernicus participating countries (European Commission, 2016b). The approach adopted by the EC follows three core principles: (a) central role of public authorities; (b) strong involvement of the commercial downstream sector and (c) leverage existing structures. This implies cross-border and cross-sectoral components, making all actors involved (such as research institutions, companies, authorities and ultimately citizens) aware of space technology as a tool for numerous applications. The democratisation of remote sensing infrastructure and tools (Lang, 2013) help turning a (formerly) key strategic asset into a ubiquitous commodity of great societal relevance.

The two organisational key elements of the user uptake concept, anchored in the European Space Agenda, are the Copernicus Relays and the Copernicus Academy (Zeil et al., 2017). Copernicus

(www.copernicus.eu/en/opportunities/public-

Relays authorities/copernicus-relays/), connoted metaphorically, are "local champions, coordinating and promoting activities around the Copernicus programme, its benefits, and opportunities for local residents and businesses" This network operates since 2017 with currently 85 global members. Complementary, the Copernicus Academy, as the name indicates, is a more academic network focusing on technological advancement and scientific findings, but also includes a range of research and development (R\&D) oriented companies and even authorities. It is a key networking instrument to ensure the overall uptake process through knowledge exchange among all actors involved, notably research and educational institutions, industry, and the public sector.

\subsection{Copernicus Academy}

The Copernicus Academy network (www.copernicus.eu/en/opportunities/education/copernicusacademy/) connects universities, research institutions, business schools, private and non-profit organizations with the aim to facilitate cooperation in research, education and training. It links research and academia with public authorities, service providers and citizens to boost the use of Copernicus data, information services and capacity building activities. With currently more than 160 members, this network has been growing into a rare pool of experts from different domains and nations, in- and outside of Europe, with the ambition to have impact on global scale.

The Copernicus Academy embraces members willing to become pioneers, bench markers and ambassadors of the knowledge potential behind Copernicus data and information (Zeil et al., 2017). Each member acts as multiplier developing initiatives to reach the development of interdisciplinary and international masters and educational classes, new skills boosting programmes for vocational training, industry- university traineeships agreements, facilitating spin-offs creation, best practices building and reference tools and materials.

The EC encourages and supports such cooperation, interaction and best practice sharing between Copernicus members. Network-wide activities fostered by the Copernicus Support Office (CSO) stimulate and facilitate the uptake of space data and information products through boosting the development of professional skills, with a focus on merging knowledge from different sectors. The EO4GEO sector skills strategy specifically aims to improve "EO*GI awareness of and engagement with end user sectors [...] leading to increased uptake of Copernicus data and information services" (MiguelLago et al., 2019). Considering that there are numerous applications outside the usual space-related domains, it is crucial to create awareness within universities and business schools to stimulate both young and experienced people to the opportunities for their professional profile specialization.

\subsection{Strengthening the Copernicus Academy network}

The EC funded project CopHub.AC (www.cophub-ac.eu/) provides ideas to maintain, strengthen and sustain the Copernicus network through establishing Copernicus hubs as knowledge and innovation platforms (Copernicus Observer, 2019). In line with research on organizational learning, stressing the importance of knowing and valuing what others know and being able to gain access to this knowledge (Borgatti \& Cross, 2003), core activities are centered around the following main constituents of the Copernicus Academy:

(1) Invent - visualizing research outcome and distributed capacities and thus facilitating accessibility of this information

(2) Innovate - bridging the gap between academia and industry as key to innovation, fostering EO solutions to real-world problems

(3) Interact - stimulating the sharing of expertise and tools between involved stakeholders such as academic institutions, public authorities, and the private sector

(4) Inform - reaching out to the public at large and students to increase awareness about Copernicus

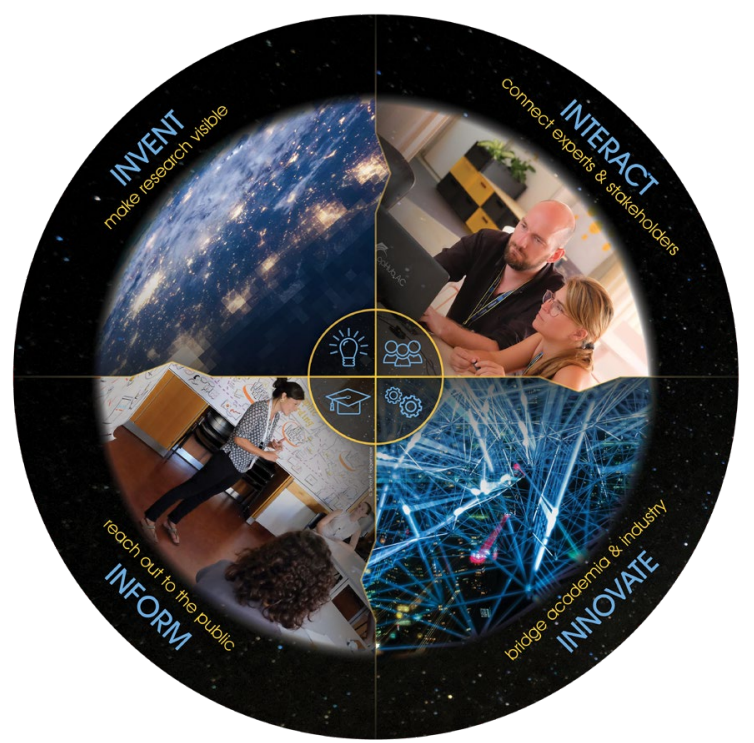

Figure 1. Core activities around the Copernicus Academy 
Building on the unique expertise of Copernicus Academy partners the aim is to link ongoing $R \& D$ activities in Copernicus-relevant academic fields foster the mutual innovation process between academia and business and increases the visibility of the Copernicus Academy as a network in a viable and sustainable way. This applies a holistic viewpoint on the opportunities and challenges of the Copernicus technological leap, its societal and economic consequences, its impact on academic education and training, and thus the complementarity of events and user groups addressed, in the spirit of the Copernicus innovation pipeline.

Considering the diversity of modern ways of communicating and disseminating research, the concept of an innovation pipeline is introduced (Fig.2). The process reflects a series of interactions between the research community and potential service providers (SMEs, start-ups, entrepreneurs, etc.) to nurture a culture of communications between these interacting groups of stakeholders - those who produce research output and those who generate services from it. It allows identification of the most impactful ways to communicate with these beneficiaries and processes to facilitate them through consideration of their needs. The innovation pipeline is regulated by an internal interaction mechanism, which is at the core of this capacity building and acts as the interface of communications between the researchers and the service providers. One such regulatory node is the Thematic working groups (see: 2.2.1). The process will be using various real life scenarios in order to shape the implementation of the innovation pipeline.

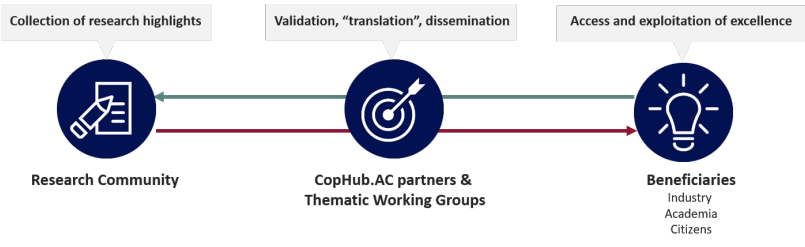

Figure 2. Innovation pipeline

\subsection{Copernicus knowledge and innovation hubs}

The concept of the Copernicus Knowledge and Innovation Hubs is built on two key elements of the European Innovation strategy: Digital Innovation Hubs (DIH) and the Open Innovation 2.0 (OI2). The concept of DIHs and the need for developing a related network was launched in 2016 through the Communication on "Digitizing European Industry" (European Commission, 2016c). DIHs can be seen as an important element in concrete territorial contexts (Rissola and Sörvik, 2018), supporting digitalization and the development of the surrounding innovation ecosystem. To facilitate digital transformation of existing industries across the European Union, different types of organizations, such as cluster organizations, regional bodies or research centres, establish DIHs. They act as a one-stop-shop for innovation enabling business to access the latest knowledge, expertise and technology for testing and experimenting with digital innovations relevant to its products, processes or business models, provide connections to investors, facilitate access to financing for digital transformations, and help connect users and suppliers of digital innovations across the value chain. OI2 is an approach for innovation focused on solving key European challenges. It is considered as a new paradigm based on a Quadruple Helix Model where government, industry, academia and civil society participants work together to cocreate the future, and drive structural changes far beyond the scope of what any one organization or person could do alone. This Open Innovation process contains five key elements: (1) networking, (2) collaboration: involving partners, competitors, universities, and users, (3) corporate entrepreneurship by enhancing corporate venturing, start-ups and spin-offs, (4) proactive intellectual property management by creating new markets for technology and (5) R\&D, which focuses on achieving competitive advantages in the market.

In alliance with DIHs and OI2, the objectives of Copernicus knowledge and innovation hubs are to boost the user uptake and development of information services, facilitate an effective transfer of knowledge, encourage cooperation, explore synergies and increase targeted capacity building and training through the implementation of two forms of Copernicus hubs:

(a) Virtual hubs - the main focus is the development of technical elements to visualize and facilitate easy harvesting of the Copernicus Academy member's expertise, both within the network and for potential external cooperation partners, open the Academy to the general public and facilitate virtual information and training events. Such hubs are considered clusters in a virtual knowledge space that represent the Copernicus Academy as a living network in response to societal change. It considers the dynamic nature of emerging knowledge areas, proliferation of new methods and disruptive changes of technologies in the era of big EO data (e.g. Sudmanns et al., 2019), the related likely shift of required competences and specialisations (Hofer et al., 2019), and the general evolvement of societal awareness and digitalisation.

(b) Regional hubs - leaning on the concept of DIHs, these physically implemented hubs focus on the interaction with local and regional stakeholders and the organization of regionspecific implemented outreach and education events. Being equipped with a rich technological and organisational infrastructure, such hubs showcase, impart and uptake the Copernicus mission either in a specific thematic field or following a trans-domain orientation reaching out and bringing together actors on various levels.

\section{ELEMENTS OF VIRUTAL COPERNICUS HUBS}

\subsection{Visualization and retrieval of members' expertise}

One key element to facilitate cooperation and knowledge transfer is that stakeholders have access to information they need. To accomplish this, the following technical features are designed to visualize the geographic distribution of capacities in methods and application fields, educational offers, as well as innovation achievement of the Copernicus Academy network.

2.1.1 Gateway: As the backbone of dynamic visualisation approaches, a new application form for the Copernicus Academy is promoted that adds to the capturing of organizational details, the retrieval of information about educational offers and cooperation with other Copernicus Academy members (www.cophub-ac.eu/application/). Potential members provide additionally a thorough, ranked-based selfassessment in the following fields:

- Methodological expertise - competence in state-of-the-art technology and methods of Geovisualisation, Spatial analysis, 
Image processing and analysis, Data integration and assimilation, Big (Earth) data" and Geo-AI.

- Copernicus services - expertise and involvement in the six Copernicus services

- Application areas - thematic expertise in selected fields focusing on current societal challenges, such as Climate change mitigation and adaptation and Food security and sustainable agriculture (Fig.3)

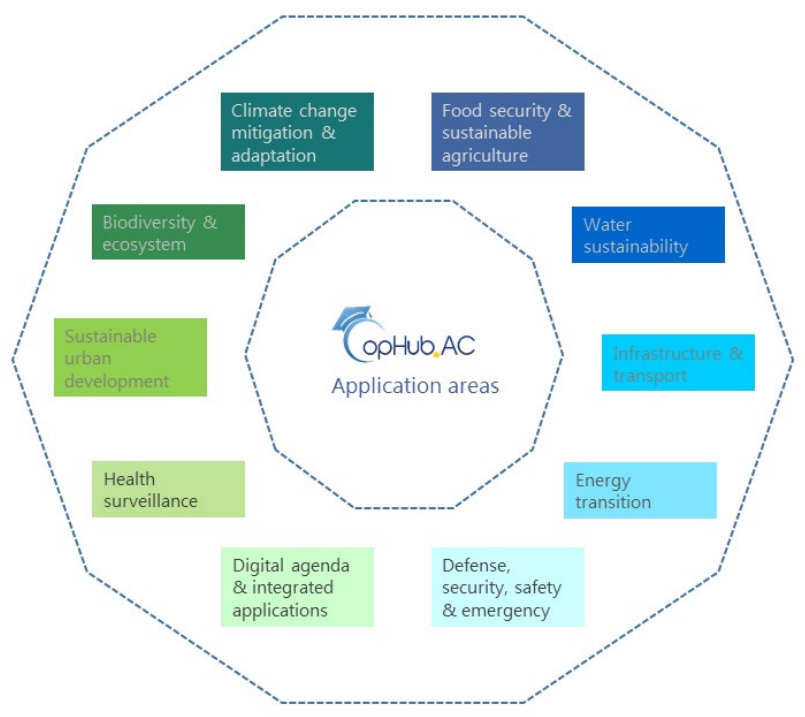

Figure 3. Gateway - application areas

To enhance the mutual understanding of which capacities are available and what is offered, a specific taxonomy is used. This taxonomy is not only considered as a process of naming and classifying above mentioned EO services and application areas, but through its close link to the EO4GEO Body of Knowledge in the EO*GI sector (Stelmaszczuk-Gorska M.A. et al., 2020) and the EARSC thematic taxonomy (EARSC, 2015) a tool to improve the understanding between communities.

2.1.2 Knowledge Landscape: To facilitate an easy retrieval of the member's capacities and expertise for potential regional and international cooperation partners, a dynamic visualization approach in form of a Knowledge Landscape is implemented (www.cophub-ac.eu/knowledge-landscape/), built on data collected in the Gateway (see 2.1.1.) and stored in a common database. To visualize geographical hot spots of competences and the geographic pattern of distributed know-how within the Copernicus Academy network, heat maps based on selfassessment data are produced using kernel density estimation (deSmith et al., 2018; ESRI, 2020) as interpolation method. In addition to the availability of detailed information about specific member institutions, a dynamic visualization approach is chosen that serves not only as a tool for communication, but also exploration - enabling selection, grouping and regrouping as well as filtering of parameters in form of a problem-solving loop (Ware, 2013). This enables a user-specific search of expertise by location, application area, methodological background and types of activity. As an analytical tool, the capacities of Copernicus Academy members are also retrievable through combined filter options, e.g. thematic competences in combination with methodological expertise (Fig.4).

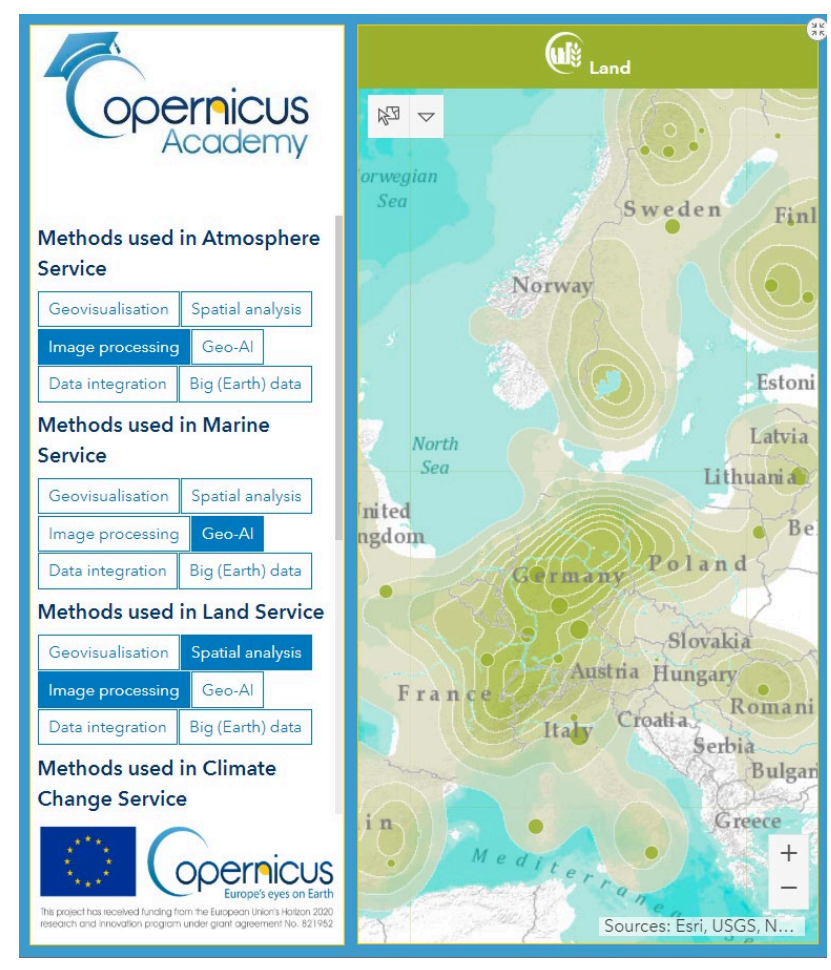

Figure 4. Knowledge Landscape (note that currently synthetic data are used for testing purposes)

2.1.3 Innovation Monitor: In order to represent the innovation capacities of Copernicus Academy members in a quantified way, an Innovation Monitor including the visualization of an Innovation Landscape is developed. For a comparable assessment of the innovation process from academia to businesses, a composite indicator-based approach (Nardo et al., 2008) resulting in one innovation index, is chosen. Taking the measure framework of the European Innovation Scoreboard (Hollanders et al., 2019a) and the Regional Innovation Scoreboard (Hollanders et al., 2019b) into account, conceptually similar indicators are selected. The indicators related to the Copernicus Academy network are measured on a different level than those of both Scoreboards and are foreseen to follow the "EO maturity indicators" methodology for the assessment and monitoring of EO activities in a given country and their evolution over time (Miguel-Lago et al., 2018). Data sources are the proposed Gateway (see 2.1.1.), constantly updated through reports and complemented by information retrieval from the semantic web. The indicators are grouped in five dimensions, each representing a different aspect of innovation (Fig.5):

- Innovators - addresses innovation through the competitiveness of the EO user uptake, but is also a trusted indicator of how a member will develop in the near future

- Linkages \& Partnerships - reflects established cooperations with different stakeholders

- Excellence of research system - represents the collaborative character of institution and scientific output

- Copernicus related activities - reflects the participation in Copernicus events and networks, use of Copernicus data, development of related training material and involvement in Copernicus services

- Education - indicates efforts towards increasing EOawareness in educational offers, including life-long learning 


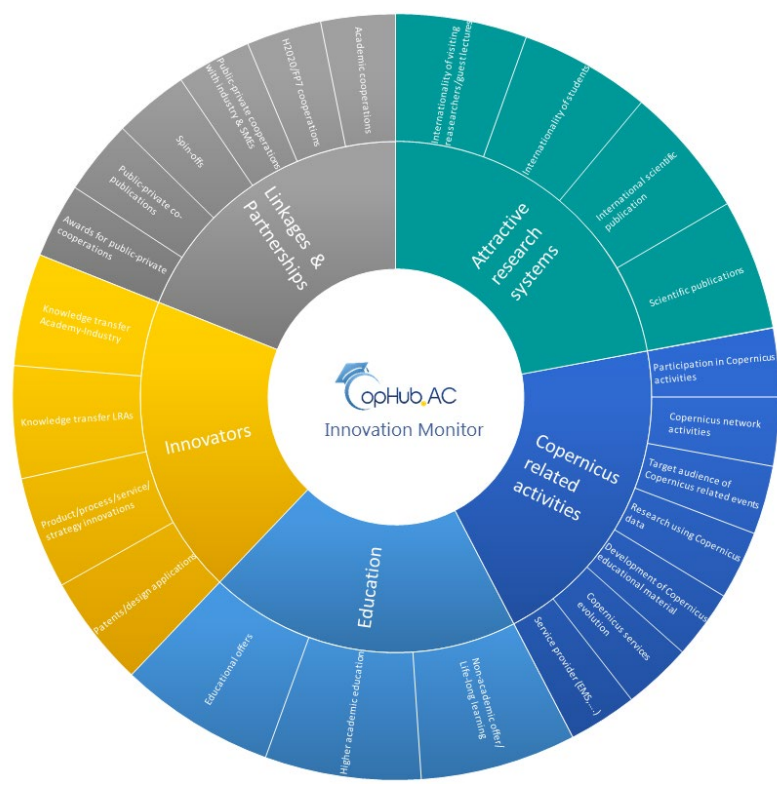

Figure 5. Innovation monitor - dimensions and indicators

Similar to the Knowledge Landscape (see 2.1.2), interpolation of this information results in the Innovation Landscape, including a decomposition of the overall innovation index to showcase the individuals strength of each Copernicus academy member (www.cophub-ac.eu/innovation-monitor/).

\subsection{Active involvement in the network}

Stimulating interaction and exchange of novel ideas and tools is vital for a living network. Efforts of active involvement within the Copernicus Academy network and means of reaching out to experts, students and the broad public are highlighted.

2.2.1 Thematic Working Groups: As in long-standing academies (of science), the participation of its members is best organised through working groups or committees that focus on specific thematic areas of expertise and respond to specific research and policy questions related to emerging societal challenges. This principle was adapted to the Copernicus Academy by setting up the Thematic Working Groups (TWG) around the Copernicus Services (www.cophub-ac.eu/thematicworking-groups/). The objective of the TWGs is to capitalise on the excellence of the Copernicus Academy members by providing research results to the Copernicus stakeholders in a systematic way. This uncaps innovation potentials in the thematic areas of Copernicus and establishes new research lines based on exchange and collaboration among TWG participants. Through its thematic focus, it will support the Entrusted Entities in the evolution and development of the Copernicus Services. As one branch of the Copernicus user uptake activities, the Copernicus Academy through its working groups serves as a pool of experts that is in a position to provide evidence-based replies to thematic requests of Copernicus stakeholder from industry or public authorities. It will produce peer-reviewed statements on key topics of Copernicus applications related to current policy frameworks such as the Sustainable Development Goals or the EU Green Deal.
So far, 54 experts from 27 Copernicus Academy members are registered in the TWGs, with a major involvement in the thematic area Land, Climate Change and Emergency. Active participation is ensured through regular teleconferences and online repositories of working documents. Special sessions are organised to focus on key topics of the Copernicus evolution.

2.2.2 Citizen app: The Citizen app provides information about the Copernicus Academy and the Copernicus services to the interested public as well as actively engaged citizens (www.cophub-ac.eu/citizen/). Copernicus information is combined with a GeoCitizen approach (Atzmanstorfer et al., 2014) to actively support the Copernicus Academy show-cast Copernicus services to the broad public through the provision of interactive possibilities to communicate with experts from the TWGs (see 2.2.1). The interaction takes place on a web map visualizing freely available information of Copernicus services such as temperature, soil moisture or air quality provided as Web Map Services (WMS) or downloadable data. Users can post questions about local layer information by indicating their position directly on the map. Local Copernicus Academy members (e.g. from the dedicated TWG) will then answer such inquiries. The technical background is a state-of-the-art progressive web app, which combines features offered by most modern browsers with the benefits of a mobile experience. Advantages of this approach are that only the website is coded which can be transformed to a, for the user normal, mobile app, for Android and iOS with no need to design web services for different platforms (Kaushik, 2019).
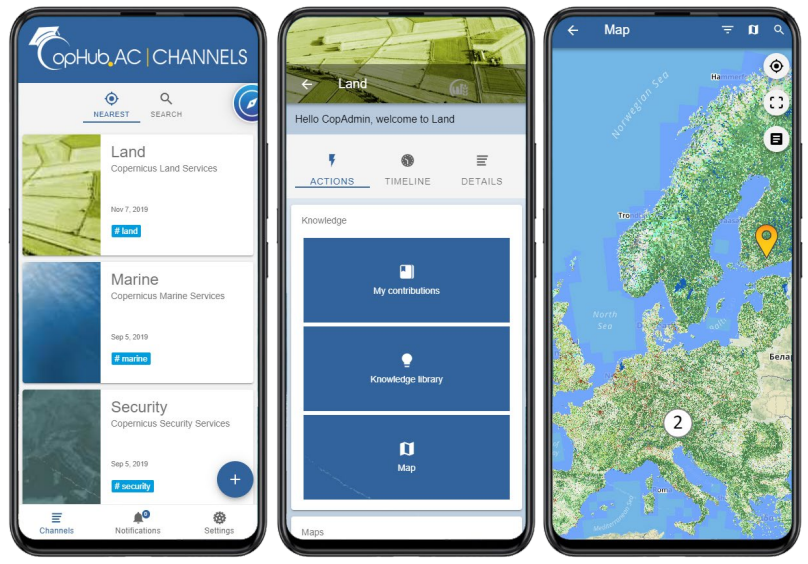

Figure 6. Citizen App

2.2.3 Partnership award: To recognise outstanding cooperation in the context of the Copernicus user uptake, a yearly Partnership Award "from Research to Market" is bestowed (2020 Award: www.earsc.org/news/partnershipaward-from-research-to-market-2020). It rewards the best collaboration, recognizing organizations leading edge achievements in pilot EO activities. Specifically, academia and companies (in partnership) are encouraged to submit proposals for cooperation or present an already established collaboration achievement. The award provides a mechanism to appreciate excellence, value creation, sustainability but also exemplary communication of results and engagement and is embedded under the EARSC Awards schema. 
2.2.4 Training: Copernicus-related training increase awareness about Copernicus and its services, strengthen the user uptake, and share expertise between different stakeholders. Remote training such as webinars and massive open online courses (e.g. the freshly started Copernicus MOOC) offer a possibility to engage different people and are increasingly recognized in higher education in Europe (Witthaus et al., 2016). In the Copernicus context, excellent training has been for many years provided through the Research and User Support for Sentinel Core Products (RUS) or Copernicus Services initiatives (e.g. C3S User Learning Services). Complementary to these, events with a local focus are promoted to meet regional needs. A suggested 'multi-level' character of such events entails involvement of actors representing different levels of the Copernicus ecosystem with a stimulating mix of opinion leaders, early adaptors, decision makers, renowned scientists, leading individuals, business angles, entrepreneurs and students. One example of a problem-solution based approach bringing different actors together - public authorities with real-world problems, researchers with methodological competence, institutional representatives with the view of operational implementation and students with innovative ideas -

is the Virtual Summer School OBIA for the operational Copernicus service challenge organized by the Salzburg regional hub (see 3.3.).

\section{EXAMPLES OF REGIONAL COPERNICUS HUBS}

Regional hubs, essential to meet local needs for exchange with stakeholders and specific training can be implemented in different forms and with different focus. Three examples are highlighted below showing this variety from a dedicated Centre of Excellence, a region with strong Copernicus Academy and Relay synergies, to a setting with educational and outreach focus with a trans-boundary effect.

\subsection{Centre of Excellence}

The ERATOSTHENES Centre of Excellence (ECoE) on Earth Surveillance and Space-Based Monitoring of the Environment in Cyprus, is established the through 'EXCELSIOR' H2020 Widespread Teaming project (www.excelsior2020.eu/). It collaborates with the German Aerospace Centre (DLR), the National Observatory of Athens (NOA), Leibniz Institute for Tropospheric Research (TROPOS) and the Department of Electronic Communications of the Deputy Ministry for Research, Innovation and Digital Policy (DEC) and is actively supported by more than 95 organizations, including ministries from the Cyprus government, municipalities, national-level organizations and networks (e.g., the Cyprus Scientific and Technical Chamber), international organizations (e.g. GEO, ESA, NASA, ISPRS, NEREUS, ACTRIS, EARLINET, EARSel, CSO), Universities (Tel-Aviv University, Aristotle University, National Technical University of Athens, BenGurion University, CNR-Italy), research centres, innovation institutions and companies. One of the main concepts of the $\mathrm{ECoE}$ is to be a fully functional regional innovation hub and European Copernicus focal point for EO related activities and developments in the Eastern Mediterranean, Middle East and North Africa region (EMMENA). It adopts a two-axis model, creating an ecosystem where the state-of-the-art sensing equipment, cutting-edge research, targeted education services and entrepreneurship come together in the three thematic cluster areas of environment and climate, resilient society and big earth data analytics (Hadjimitsis et al., 2020a, 2020b).

\subsection{Joint Copernicus Academy and Relay hub}

In the BASILICATA region of Italy, the space sector, with a particular reference to the applications of EO technologies for the environmental monitoring and natural risks prevention, is well established due to the presence of public research centres (National Research Council, Italian Space Agency, ENEA), the University of Basilicata (Unibas), consortia of small and medium-sized enterprises (Createc), TeRN (Technologies for natural risk and Earth observation) and large national players such as E-Geos. Such a concentration of excellence has fostered the realization of a regional Copernicus hub demonstrating advantages of synergies between the Copernicus Academy and Copernicus Relays network with the joint aim to strengthen the role of the region of Basilicata by fostering the development of a regional EO-based business market and increasing awareness of the potential of EO data and service. It involves Unibas - one of the main proposers of the Salzburg Declaration (GMES4Regions, 2012), Copernicus Academy member and in the consortium of CopHub.AC and TeRN - one of the first established Copernicus Regional Contact Offices (RCOs), a member of the Copernicus Relays network and partner in the project CoRdiNet. Due to a joint participation in mentioned projects, several coordinated activities have been carried out to promote Copernicus user uptake among local public administrations, SMEs and professionals with a particular focus on existing gaps in the field of training and education. As an example to bring students and potential users (and job providers) together, a Young Copernicus Ambassador Day (Satriano et al., 2020) was organized, where students present their Copernicus-based solutions to the problems previously posed by potential end-users, who got the possibility to move from their "desiderata" to (often unexpected) Copernicus based solutions.

\subsection{Education and outreach hub}

The SALZBURG setting at the Austrian-German border is established around a vibrant cluster of academic and nonacademic research institutions as well as a decent set of highly specialised SMEs, actively promoting and applying EO*GI competence since several decades. This regional hub is spearheaded by the Department of Geoinformatics Z_GIS (www.zgis.at/) a unique EO*GI competence centre and founding member of the Copernicus Academy (GMES4Regions, 2012), coordinator of the H2020 project CopHub.AC, academic coordinator of the ERASMUS+ project EO4GEO and host of the first Copernicus-related ERASMUS+ European Joint Masters (http://cde.sbg.ac.at/). With a clear transboundary mission, the hub offers a unique infrastructure for experiencing and learning GI and EO technologies, hosting the award-winning iDEAS:lab (www.ideaslab.sbg.ac.at/), where experts, scientists, entrepreneurs and the interested public can get in touch with latest advances in the Digital Earth vision, and a Copernicus mini mundus with data access to in-situ and satellite repositories. It has long-term experience in GI/EOrelated R\&D\&I activities, being one of the academic founders of the globally adopted Object-based Image Analysis (OBIA) approach (Lang et al. 2019a), co-shaping EO-based information products in several service domains (Lang et al. 2019b, Lang et al. 2015), translating user needs into service elements and design and providing conceptual and technical key contributions to the 'big Earth data' paradigm (Sudmanns et al. 2019). In addition to the higher educational offers form of BSc, MSc and structured $\mathrm{PhD}$ programs (www.dkgiscience.zgis.net/), Z_GIS offers opportunities for regularly 
life-long training through single events such as Summer Schools, including virtual ones (see: 2.2.4), established distance learning programs (UNIGIS: www.unigis.at/) and businessoriented training. Events bringing together science, business, and the community of practice are e.g. the widely known AGIT and GI_Forum conferences, bundled with other international symposia (such as EARSeL, ISDE) in the GI Week early July of every year.

\section{CONCLUSION}

The term 'Copernicus ecosystem' demonstrates the growing complexity and interconnectivity emanating from the innovative European Information Service Programme. The paradigm shift through free, open and accessible provision of harmonized data unlashes cascades of inventions ready for uptake by industry to supply innovative solutions for societal challenges. The main role of the Copernicus knowledge and innovation hubs, according to our definition, is to facilitate this process from invention to innovation, encourage cooperation of all involved stakeholders and facilitate targeted capacity building and training measures. Regionally manifested - here demonstrated by the three examples - and embedded in the virtual knowledge space, the means of facilitation are manifold, and can be adapted to specific thematic and spatial contexts. We suggest the developed elements for virtual hubs as a first set of measures to support these physical implemented hubs and overall improve and sustain the crucial function of the Copernicus Academy Network in the Copernicus ecosystem.

\section{ACKNOWLEDGEMENTS}

The research implemented in the project CopHub.AC has received funding from the European Union's Horizon 2020 research and innovation program under grant agreement No. 821952.

\section{REFERENCES}

Atzmanstorfer, K., Resl, R., Eitzinger, A., X. Izurieta, X., 2014. The GeoCitizen-approach: Community-based Spatial Planning. An Ecuadorian Case Study. Cartography and Geographic Information Science, 41, 3, pp. 248-259.

Borgatti, S.P., Cross, R., 2003. A Relational View of Information Seeking and Learning in Social Networks, Management Science Informs, 49, 4, pp.432-445

Copernicus observer, 2019. Strengthening the research \& development \& innovation capacity for the evolution of Copernicus, $\quad$ www.copernicus.eu/en/news/news/observerstrengthening-research-development-innovation-capacityevolution-copernicus (5 May 2020).

deSmith, M.J., Goodchild, M.F., Longley, P.A., 2018: Geospatial Analysis - A Comprehensive Guide to Principles, Techniques and Software Tools, Sixth Edition, 2018-2, www.spatialanalysisonline.com (4 May 2020).

EARSC, 2015. A Taxonomy for the EO Service Market: enhancing the perception and performance of the EO service industry.

http://earsc.org/file download/489/A+Taxonomy+for+the+EO+ Services + Market + issue $+2+\% 282 \% 29 . p d f(5$ May 2020).
ESRI, 2020. ArcGISPro Online Manual - Kernel Density, https://pro.arcgis.com/en/pro-app/tool-reference/spatialanalyst/kernel-density.htm (4 May.2020).

European Commission, 2016a. Directorate-General for Internal Market, Industry, Entrepreneurship and SMEs Space Strategy for Europe, $\operatorname{COM}(2016) \quad 705$ final, https://ec.europa.eu/transparency/regdoc/rep/1/2016/EN/COM2016-705-F1-EN-MAIN.PDF (5 May 2020).

European Commission, 2016b. Copernicus User UptakeEngaging with public authorities, the private sector and civil society. Final Version. https://www.copernicus.eu/sites/default/files/201810/Copernicus_User_Uptake_Engaging_with_Users_0.pdf (5 May 2020).

European Commission, 2016c. Communication on Digitising European Industry - Reaping the full benefits of the Digital Single Market, https://eur-lex.europa.eu/legalcontent/EN/TXT/?uri=CELEX:52016DC0180

(5 May 2020).

GMES4Regions, 2012. Salzburg Declaration on GMES-related Research,

http://www.cccartografica.cat/catl/content/download/53814/370 213/file/Salzburg_Declaration_on_GMES-related_research.pdf (5 May 2020)

Hadjimitsis, D., Schreier, G., Kontoes, H., Ansmann, A, Komodromos, G., Themistocleous, K., Neocleous, K., Michaelides, S., Mamouri, R. Papoutsis, I., Bühl, J., Schwarz, E., Melillos, G., Tziortzis, S., Danezis C., Nisantzi, A., Mettas, C., Papoutsa, C., Tzouvaras, M., Evagorou, E., Agapiou, A., Miltiadou, M., Christofe, A., Prodromou, M., Loulli, E., Yfantidou, A., Alverti, M., Lysandrou, V., Polydorou, T., Kyriakidis, P., Kyriakides, N., Akylas, E., Anayiotos, A., Ambrosia, V., Maranesi, M., Zeil, P., Halounova, L., Barok, D., Cheli, S., 2020a. The ERATOSTHENES Centre of Excellence (ECoE) as a digital innovation hub for Earth observation, Proc. SPIE 11418, Detection and Sensing of Mines, Explosive Objects, and Obscured Targets XXV,114180F.

Hadjimitsis, D., Schreier, G., Kontoes, H., Ansmann, A, Komodromos, G., Themistocleous, K., Neocleous, K., Michaelides, S., Mamouri, R. Papoutsis, I., Bühl, J., Schwarz, E., Tziortzis, S., Nisantzi, A., Mettas, C., Papoutsa, C., Danezis, C., Tzouvaras, M., 2020b. The "Excelsior" H2020 Widespread Teaming Phase 2 Project: ERATOSTHENES: EXcellence Research Centre for Earth SurveiLlance and Space-Based Monitoring Of the Environment, EGU General Assembly 2020, EGU2020-21836.

Hofer, B., Lang, S., Ferber, N., 2019. Future Occupational Profiles in Earth Observation and Geoinformation - Scenarios Resulting from Changing Workflows. In: Kyriakidis P., Hadjimitsis D., Skarlatos D., Mansourian A. (eds) Geospatial Technologies for Local and Regional Development. AGILE 2019. Lecture Notes in Geoinformation and Cartography. Springer, Cham.

Hollanders, H., Es-Sadki, N., Merkelbach, I., 2019a. European Innovation Scoreboard 2019, European Union, 2019, https://ec.europa.eu/docsroom/documents/38781 (4 May 2020). 
Hollanders, H., Es-Sadki, N., Merkelbach, I., 2019b. Regional Innovation Scoreboard 2019, European Union, 2019, https://ec.europa.eu/growth/sites/growth/files/ris2019.pdf May 2020).

Lang, S., 2013. Ideas into action. Public Service Review: European Union (Vol. 23).

Lang, S., Mairota, P., Pernkopf, L.,Schioppa, E. P., 2015. Earth observation for habitat mapping and biodiversity monitoring. International Journal of Applied Earth Observation and Geoinformation, 37, pp. 1-6.

Lang, S., Hay, G., Baraldi, A., Tiede, D., T., Blaschke, T., 2019a. GEOBIA achievements and spatial opportunities in the era of big Earth observation data. ISPRS International Journal of Geo-Information, 8, pp. 474-483.

Lang, S., Füreder, P., Riedler, B., Wendt, L., Braun, A., Tiede, D., Schoepfer, E., Zeil, P., Spröhnle, K., Kulessa, K., Rogenhofer, E., Bäuerl, M., Öze, A., Schwendemann, G., Hochschild, V., 2019b. Earth observation tools and services to increase the effectiveness of humanitarian assistance. European Journal of Remote Sensing, pp. 1-19.

Miguel-Lago, M., Mamais, L., Konotes, H., Tsouni, A., 2018. Assessing the maturity of EO activities at national level, 69th International Astronautical Congress (IAC), 1-5 October 2018, Bremen, Germany.

Miguel-Lago, M., Bansal, R., Ramirez, K., Gomarasca, M., Donnelly, R., Martirano, G., Carbonaro, M., Gorni, S., Molina, R., Saio, G., De Brito, M., Vancauwenberghe, G., Vandenbroucke, D., Ferber, N., Hofer, B., Lang, S., Zeil, P., Satriano, V., Scanniello, G., Tramutoli, V., 2019. Space/Geospatial Sector Skills Strategy (EO4GEO) https://bit.ly/2zXySxc (6 May 2020).

Nardo, M., Saisana, M., Saltelli, A., Tarantola, S., Hoffman, A., Giovannini, E., 2008. Handbook On Constructing Composite Indicators: Methodology And User Guide. EC Joint Research Centre \& OECD Statistics Directorate and the Directorate for Science, Technology and Industry.

Kaushik, Gaurav, 2019. Progressive Web App - The future of Web Development. International Journal for Research in Applied Science and Engineering Technology. 7. pp. 495-498.

Stelmaszczuk-Górska, M.A., Aguilar-Moreno, E., Casteleyn, S., Vandenbroucke, D., Miguel-Lago, M., Dubois, C., Lemmens , R., Vancauwenberghe, G., Olijslagers, M., Lang, s., Albrecht, F., Belgiu, M., Krieger, V., Jagdhuber, T., Fluhrer, A., Soja, M.A., Mouratidis, A., Persson, H.P., Colombo, R., Masiello, R., 2020. Body of Knowledge for the Earth observation and geoinformation sector - a basis for innovative skills development, ISPRS this issue.

Rissola, G., Sörvik, J., 2018. Digital Innovation Hubs in Smart Specialisation Strategies. EUR 29374 EN, Publications Office of the European Union, Luxembourg.

Satriano , V., Colonna, R., Filizzola, C., Genzano, N., Lacava, T., Pergola, N.and Tramutoli, V., 2020. The Copernicus Young Ambassador Day: a replicable example for new technologies uptake by SMEs and Local Regional Authorities. EGU General Assembly 2020, EGU2020-8927.
Sudmanns, M., Tiede, D., Lang, S., Bergstedt, H., Trost, G., Augustin, H., Baraldi, A., Blaschke, T., 2019. Big Earth data: disruptive changes in Earth observation data management and analysis? International Journal of Digital Earth, 1-19.

Ware, C., 2013: Information Visualization - Perception for Design, Morgan Kaufmann, Elsevier Inc.

Witthaus, G., dos Santos, A.I., Childs, M., Tannhäuser, A.C., Conole, G., Nkuyubwatsi, B., Punie, Y., 2016. Validation of Non-fomral MOOC-based Learning - An Analysis of Assessment and Recognition Practices in Europe (OpenCred), JRC Science for Policy Report. https://publications.jrc.ec.europa.eu/repository/bitstream/JRC96 968/lfna27660enn.pdf (6 May 2020).

Zeil, P., Ourevitch, S., Debien, A., Pico, U., 2017. The Copernicus User Uptake - Copernicus Relays and Copernicus Academy. GI Forum - Journal for Geographic Information Science 1, pp. 253-259 